\section{Estudo \\ cobebate}

em Cestã⿻

Planejamento
Revista Estudo \& Debate, Lajeado, v. 25, n. 2, 2018. ISSN 1983-036X

DOI: http://dx.doi.org/10.22410/issn.1983-036X.v25i2a2018.1801

\title{
RESERVAS LEGAIS DE PROPRIEDADES RURAIS COM PRODUÇÃO DE LEITE NO VALE DO TAQUARI
}

\author{
Alexandre Batista Scheifler ${ }^{1}$, Claudete Rempel ${ }^{2}$
}

\begin{abstract}
Resumo: A Reserva Legal (RL), segundo o Novo Código Florestal Federal (NCFF), é uma área localizada no interior de uma propriedade ou posse rural, necessária ao uso sustentável dos recursos naturais, com a função de reabilitação dos processos ecológicos, conservação da biodiversidade e abrigo e proteção da fauna e flora nativa. O objetivo do trabalho foi avaliar o status quo da RL das propriedades rurais produtoras de leite do Vale do Taquari (VT), e verificar as necessidades de adequação das mesmas frente à legislação ambiental. Foram amostradas 101 propriedades rurais produtoras de leite as quais se buscou verificar o uso e a cobertura da terra em relação aos remanescentes de vegetação nativa, as Áreas de Preservação Permanente (APP) e a RL. Para tanto, foi utilizado o procedimento técnico de pesquisa de campo e documental a partir do qual foi possível concluir que as propriedades rurais produtoras de leite do VT estão atendendo aos parâmetros regimentais do NCFF em termos de RL. A pesquisa revelou a necessidade de aprofundar outros aspectos ou mesmo instrumentos que garantam a coexistência da atividade com a preservação ambiental.
\end{abstract}

Palavras-chave: Legislaçáo ambiental, uso da terra, propriedade rural, pequena propriedade rural, Cadastro Ambiental Rural - CAR.

\begin{abstract}
The Legal Reserve (LR), according to the new Federal Forest Code (NFFC), is an area located within a rural property or ownership, which is necessary for a sustainable use of natural resources, with the function of the rehabilitation of ecological processes, conservation of biodiversity, shelter and protection of the native fauna and flora. The objective of this work was to evaluate the situation of LR of small farms producing milk in Vale do Taquari (VT), and also check the needs of adequacy of the aforementioned in face of environmental legislation. A hundred and one milk producing rural properties were sampled in order to evaluate the use of land in the PPA (Permanent Preservation Area) and the remnants of native vegetation that might compose the LR. In order to study the areas, a documental and technical field research procedure was used, from which was possible to conclude that the rural milk producing properties from VL in accordance to the legal parameter stablished by the NFFC regarding the LR. Nevertheless, even if the farmers are not obliged to adequate their properties, when it comes down to LR, the present study revealed the need to dig deeper into not only other aspects but also other instruments which could assure the coexistence of this activity and the environmental preservation.
\end{abstract}

Keywords: Environmental legislation, land use and land coverage, rural property, small rural property, Rural Environmental Cadastre - REC.

1 Graduado em Gestão Ambiental e Mestre em Sistemas Ambientais Sustentáveis.

2 Bióloga. Doutora em Ecologia. Docente dos Programas de Pós-Graduação em Ambiente e Desenvolvimento e em Sistemas Ambientais Sustentáveis. 


\section{INTRODUÇÁO}

As raízes protetivas brasileiras são muito anteriores à eclosão do chamado "Ambientalismo", cujo marco inicial, para muitos, foi a Conferência de Estocolmo, em 1972. Exemplo disso está na Constituição Republicana de 1934, que foi a primeira a considerar a proteção da natureza como um princípio fundamental, tendo sido por ela atribuída à União e aos Estados, a competência para, de forma concorrente, como diz no capítulo I, Artigo 10 "proteger belezas naturais e monumentos de valor histórico e artístico" (BRASIL, 1934).

O Brasil sempre teve uma preocupação em relaçáo à manutenção de suas florestas, tanto que, o primeiro Código Florestal brasileiro foi instituído em 1934 através do Decreto $\mathrm{n}^{\circ} 23.793$, e declarou que as florestas existentes no território nacional, consideradas em conjunto, constituem bem de interesse comum a todos os habitantes, do país (BRASIL, 1934). No entanto, o presente decreto estabelecia alguns fundamentos para a proteção territorial dos principais ecossistemas florestais, porém, seu principal objetivo era a regulamentação da exploração da madeira no país (BRASIL, 1934).

No início da década de 60, foi sancionada pela Presidência da República, a Lei No 4.771 de 15 de setembro de 1965, que instituiu o "novo" Código Florestal. Esta legislaçáo extinguiu algumas tipologias definidas pelo Código de 1934, substituindo-as por outras que priorizavam conter a devastação florestal. Pode se dizer que tal legislação foi um marco para o arcabouço ambiental brasileiro, mormente, por instituir alguns conceitos novos, entre eles, o de parque nacional, floresta nacional, áreas de preservação permanente (APP) e reserva legal $(\mathrm{RL})$.

Em 1988 a Constituição Federal (CF) determinou, em seu capítulo VI, Artigo 225 que "todos têm direito ao meio ambiente ecologicamente equilibrado, bem de uso comum do povo e essencial à sadia qualidade de vida, impondo-se ao Poder Público e à coletividade o dever de defendê-lo e preservá-lo para as presentes e futuras geraçōes" (BRASIL, 1988). Esta Carta Magna foi a primeira a adotar em seu escopo o conceito de meio ambiente.

Duas décadas após a promulgação da $\mathrm{CF}$, que estabeleceu a proteção dos ecossistemas e, consagrou o meio ambiente ecologicamente equilibrado como direito fundamental (BRASIL, 1988), iniciou-se os debates em torno da alteração do Código Florestal Federal a Lei no 4.771 de 1965.

Milaré (2015) destaca que as sucessivas reformas do Código Florestal de 1965, promovidas em grande parte por Medidas Provisórias (MP), especialmente a MP 2.166-67 de 2001, fragilizaram a presente legislação.

Para Amado (2015), o antigo Código Florestal precisava ser substituído, haja vista que, foi editado em um período em que a realidade florestal brasileira era divergente da atualidade. $\mathrm{O}$ autor salienta que o novo texto trouxe várias disposiçóes mais flexíveis em favor do pequeno proprietário ou possuidor rural, especialmente no que concerne às APP e de RL. No entanto, ressalta que em determinados temas houve um retrocesso de proteção florestal, ferindo o Princípio da Vedação ao Retrocesso Ambiental, ou seja, uma nova legislação ou arcabouço jurídico, não pode ferir outra legislação vigente. Assim, no arcabouço jurídico brasileira, o princípio da proibição do retrocesso ambiental é demanda 
premente e necessária para de nortear a afirmação dos direitos estatuídos sem regredir ou voltar às práticas passadas.

Assim, após um longo debate entre congressistas, a sociedade civil e o governo, foi aprovado o NCFF - Lei no 12.651, de 25 de maio de 2012. O novo texto prevê, entre seus mais de 500 dispositivos, a manutenção de conceitos já estabelecida na legislação anterior. e estabelece normas gerais sobre a proteção da vegetação, APP e as áreas de RL, a exploração florestal, o suprimento de matéria-prima florestal, o controle da origem dos produtos florestais e o controle e prevenção dos incêndios florestais e, prevê instrumentos econômicos e financeiros para o alcance de seus objetivos.

Mesmo mantendo os preceitos para usos excepcionais já estabelecidos para as APP e RL, o legislador antecipa e condiciona que o regime de ocupação e utilização de terras agricultáveis, a título de áreas consolidadas com atividades agrossilvipastoris (SODRÉ, 2013), é autorizado, exclusivamente, à continuidade das atividades agrossilvipastoris, de ecoturismo e de turismo rural em áreas rurais consolidadas até 22 de julho de 2008 (BRASIL, 2012).

Quanto à RL, a legislação estimula e assegurar o uso econômico de modo sustentável dos recursos naturais do imóvel rural, auxiliar a conservação e a reabilitação dos processos ecológicos e promover a conservação da biodiversidade, bem como o abrigo e a proteção de fauna silvestre e da flora nativa nessas áreas. E, admite a exploração econômica da mesma mediante manejo sustentável, previamente aprovado pelo órgão estadual competente (BRASIL, 2012).

No Brasil, o módulo fiscal é uma unidade de medida, em hectares, cujo valor é fixado pelo INCRA para cada município levando-se em conta: (a) o tipo de exploração predominante no município (hortifrutigranjeira, cultura permanente, cultura temporária, pecuária ou florestal); (b) a renda obtida no tipo de exploração predominante; (c) outras exploraçóes existentes no município que, embora não predominantes, sejam expressivas em função da renda ou da área utilizada; (d) o conceito de "propriedade familiar". A dimensão de um módulo fiscal varia de acordo com o município onde está localizada a propriedade. O valor do módulo fiscal no Brasil varia de 5 a 110 hectares (EMBRAPA, s.a.) e no Rio Grande do Sul, o IBGE (2006) apontou em seu censo Agropecuário que o tamanho médio das pequenas propriedades rurais era de 16 hectares. Resultado semelhante foi notado por Cyrne (2015), em seu estudo sobre " $\mathrm{O}$ (não) uso de indicadores de gestão em propriedades leiteiras do Vale do Taquari - RS”, onde as mesmas têm em médias 16,5 hectares de extensão.

A presente pesquisa verificou o status quo da RL das pequenas propriedades produtoras de leite do Vale do Taquari, frente ao NCFF, e, verificou como é possível agregar as APPs e os remanescentes de vegetação nativas para fins de enquadramento delas na legislação vigente.

O objetivo do presente estudo foi analisar avaliar a área de possível destinação à $\mathrm{RL}$ das propriedades rurais produtoras de leite do Vale do Taquari frente os parâmetros estabelecidos pelo NCFF - Lei no 12.651 de 25 de maio de 2012. 


\section{PROCEDIMENTOS METODOLÓGICOS}

\subsection{Caracterização da pesquisa}

O modelo de procedimento técnico foi o de pesquisa de campo e documental e teve duas etapas distintas que foram seguidas:

A primeira foi feita por meio da identificação do uso da terra em que foram utilizadas ferramentas como GPS de navegação portátil (GARMIN GPSMAP $64^{\circ}$ ) e imagens digitais do Software Google Earth Pro para a elaboração de mapas que permitiram a identificação das áreas de preservação permanente, os remanescentes de vegetação nativa e a RL das propriedades.

A segunda parte do projeto consistiu na coleta de dados junto aos produtores, onde foram arguidos os dados sobre a propriedade, tais como tamanho, produção diária, quantidade de bovinos (destinação de dejetos sólidos e líquidos, qualidade da água utilizada para dessedentação animal e consumo humano, situação de uso e cobertura da APP e RL, prática de queimadas, erosão do solo, diversidade de culturas, forma de utilização e armazenamento de agrotóxicos e declividade do terreno aferidas em campo). Estes dados foram compilados em tabela e confrontados com os mapas para a exposição de sugestóes para a averbação da RL, quando o produtor não realizou o Cadastro Ambiental Rural CAR.

\subsection{Coleta de Dados}

Para estabelecer proporcionalmente as unidades amostrais levou-se em consideração o número de propriedades rurais existentes em cada município pertencente à região do Vale do Taquari, a partir dos dados do último Censo Agropecuário, do Instituto Brasileiro de Geografia e Estatística (IBGE, 2006) de modo que a amostra tivesse 95\% de confiança.

As Secretarias de Agricultura e a Empresa de Assistência Técnica e Extensão Rural (EMATER) indicaram 101 propriedades rurais produtoras de leite participantes da pesquisa (FIGURA 1). Ressalta-se que a localização espacial das propriedades não é demonstrada devido a um acordo firmado com os produtores, para a não identificação das mesmas. 
Figura 1. Mapa da região do Vale do Taquari, Rio Grande do Sul, Brasil, com a indicação do número de propriedades avaliadas por município

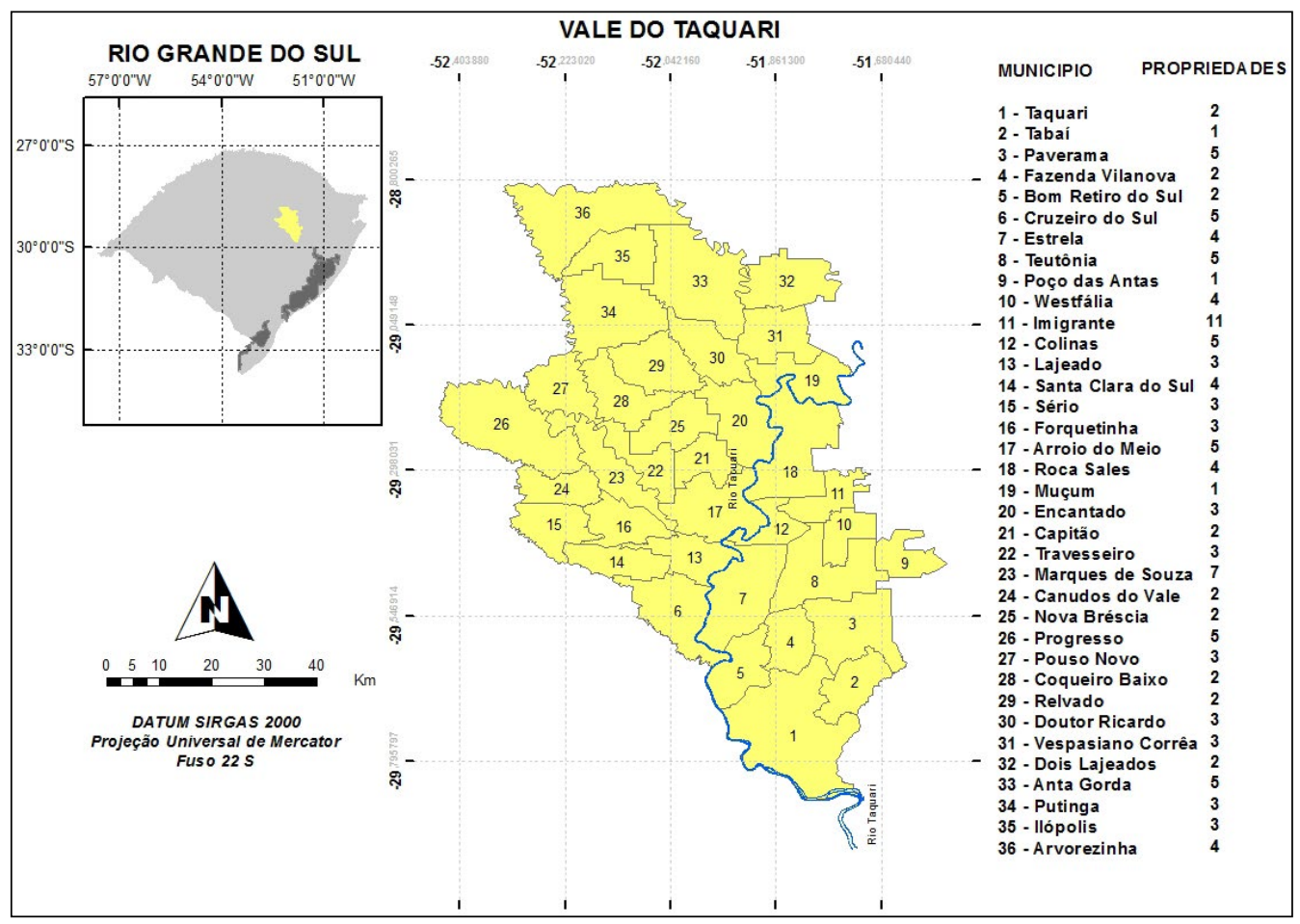

Fonte: Elaboração de Maico Fernando Herrmann (2016).

A pesquisa avaliou 101 propriedades rurais, produtoras de leite, nos 36 municípios do Vale do Taquari, e que estáo inseridas em um Grupo de Pesquisa em Sustentabilidade de Propriedades Rurais Produtoras de Leite da Univates.

Para a realização desse trabalho foram utilizados os seguintes materiais e softwares:

- Imagem do Google Earth com a localização da propriedade;

- GPS navegação portátil (GARMIN GPSMAP $64^{\circledR}$, precisão de cerca de 3,65 m) para coleta das coordenadas nas propriedades;

- Software AutoCad 2014 para a confecção dos mapas;

- Software Microsoft Excel 2010 para a tabulação dos dados.

A partir da análise do Roteiro de Perguntas, foram extraídas informações necessárias para uma análise da situação de uso da terra das propriedades e suas principais atividades, visando a determinação da situação da RL das propriedades em estudo, verificando-se se as propriedades já averbaram a RL no CAR ou se há área com vegetação nativa original pronta para averbação no órgão estadual competente, no caso do Rio Grande do Sul, a FEPAM Fundação de Proteção Ambiental. 
Por meio de imagem de alta resolução espacial do Google Earth foram digitalizadas as áreas de todas as propriedades, e, com os dados informados pelos funcionários das secretarias municipais, foram levadas a campo para verificação e ajustes in loco.

Com o auxílio do GPS navegação portátil (GARMIN GPSMAP $64{ }^{\circ}$ ) anotou-se os vértices das coordenadas das propriedades com a ajuda dos proprietários. A partir da análise do questionário, das imagens de satélites e dos dados coletados em campo foi possível identificar os elementos naturais encontrados e os tipos de usos e coberturas quanto às APP e seus remanescentes de vegetação nativa que poderão compor a RL.

Para a realização do esboço do mapa em cada propriedade, por orientação dos proprietários, foi solicitado a indicar a existência e o posicionamento das nascentes, cursos d'água, olhos d'água e os remanescentes de vegetação nativa, sendo registradas as coordenadas geográficas com o GPS para facilitar a demarcação das APP desses pontos. A quantidade de pontos registrados em cada propriedade rural variou de acordo com o número de nascentes, cursos d'água e diferentes usos. Ainda foi realizado um levantamento dos vértices de cada propriedade e elaborado um mapa do uso da terra com a indicação das respectivas APP de recursos hídricos e os remanescentes de vegetação nativa para indicação no CAR como a RL.

Os dados obtidos nas entrevistas e os mapas confeccionados foram utilizados para verificar se existe alguma variável da propriedade que interfira na conservação dos fragmentos florestais e para realizar o comparativo entre as propriedades estudadas.

Os fragmentos em APP e em RL foram observados a partir de imagens de satélite disponíveis no software gratuito Google Earth, antes de iniciar o levantamento da vegetação. Cada fragmento recebeu uma numeração e teve seus contornos estabelecidos com a ferramenta "Adicionar Caminho". O caminho criado foi salvo em formato KML. Para importar os dados do contorno dos fragmentos no aparelho de GPS (Global Positioning System), utilizou-se software gratuito GPS TrackMaker. O caminho em formato KML foi aberto neste software e a ferramenta "GPS navegação portátil (GARMIN GPSMAP $644^{\circledR}$ ), foi a importação dos dados no GPS.

O mapeamento das propriedades rurais foi realizado de forma a contemplar a delimitação das RL conforme determina o NCFF em seus dispositivos permanente e transitórios e demais legislaçóes pertinentes.

\subsection{Elaboração dos mapas e tabulação dos dados}

Concomitantemente à elaboração dos mapas, foram feitas as visitas às propriedades onde foram feitas as entrevistas e à anotação das condições observadas nos parâmetros analisados. Nas atividades de campo foi realizada a aferição das coordenadas UTM com um GPS, para exatidão das demarcaçóes realizadas na imagem via satélite da propriedade e coletado o ponto de algumas APPs entre elas as nascentes.

Em laboratório foi realizado o desenho, no software AutoCad 2014, em modelo padrão para todos os mapas, do croqui da situação, fazendo as delimitaçóes dos devidos usos, a partir da imagem de satélite disponibilizada via Google Earth. 
Com o software AutoCad 2014 foram confeccionados os mapas de cada propriedade visitada. Nos mapas foram demarcadas as APP como curso d'água natural perene e intermitente, excluídos os efêmeros, áreas no entorno dos reservatórios d'água artificiais, decorrentes de barramento ou represamento de cursos d'água naturais, áreas no entorno das nascentes e dos olhos d'água perenes remanescentes de vegetação nativas, florestas exóticas, açudes.

Após elaboração dos mapas ocorreu a interpretação e tabulação dos dados no software Microsoft Excel 2010, onde foram anotados os valores das áreas de cada APP bem como o percentual de cada uso da terra encontrados nelas. Em seguida, na planilha foram calculadas as porcentagens encontradas em cada uma delas.

\section{RESULTADOS E DISCUSSÃO}

Foram avaliadas 101 propriedades rurais produtoras de leite avaliadas do VT. Podese observar que 53 delas têm menos de um módulo fiscal, ou seja, menos de 18 hectares (FIGURA 2). O levantamento apontou que 41 propriedades têm entre 1,1 e 2 módulos fiscais (18 a 36 ha), e, apenas sete propriedades têm mais de 2,1 módulos fiscais (mais de 36 ha) e nenhuma possui mais do que 4 módulos fiscais.

Figura 2 - Propriedades rurais produtora de leite do VT de acordo com a quantidade de módulos fiscais de cada município

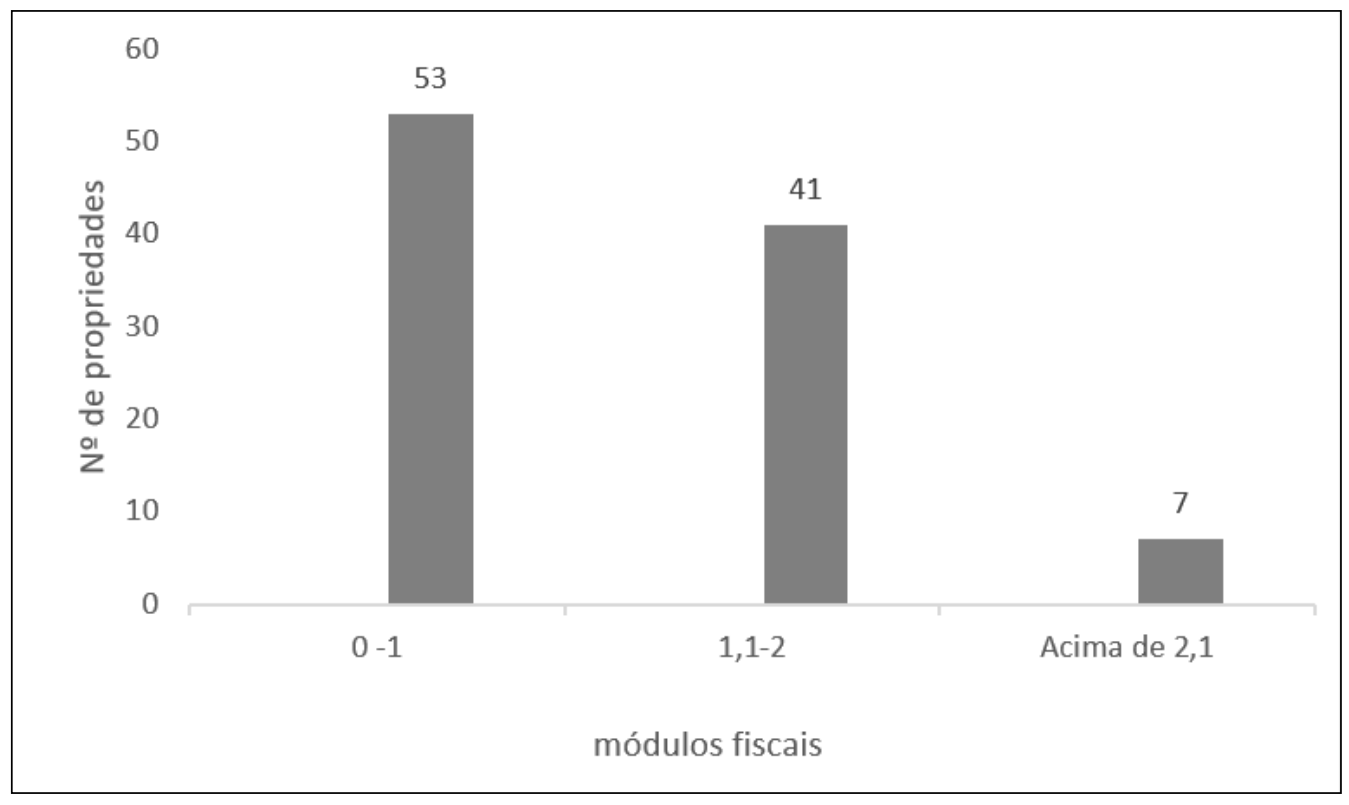

Fonte: Dados da Pesquisa (2017).

Como uma forma de conhecer as propriedades náo somente pelas suas extensóes de área, mas também por sua produção, foi necessário um levantamento do rebanho e do uso da terra. 
O rebanho bovino do VT é de 247.480 bovinos e estão distribuídos em 13.936 propriedades rurais em 36 municípios (FIGURA 3). Enquanto que a amostra da pesquisa é de 101 propriedades que detém um rebanho de 4.119 bovinos.

Segundo Ribeiro, Brites e Junqueira (2006), a atividade agropecuária é vista como uma das principais vilãs do meio ambiente devido ao elevado potencial de danos que pode causar. Para os autores, independente da atividade que desenvolvem, do nível tecnológico e de seu tamanho, exige-se que produtores rurais adotem práticas visando não apenas a obtenção de lucros, mas também a utilização planejada dos recursos naturais, acarretando assim o equilíbrio entre a atividade exercida e a conservaçáo do ambiente.

Figura 3 - Apresenta a caracterização das propriedades e do rebanho bovinos por município do VT

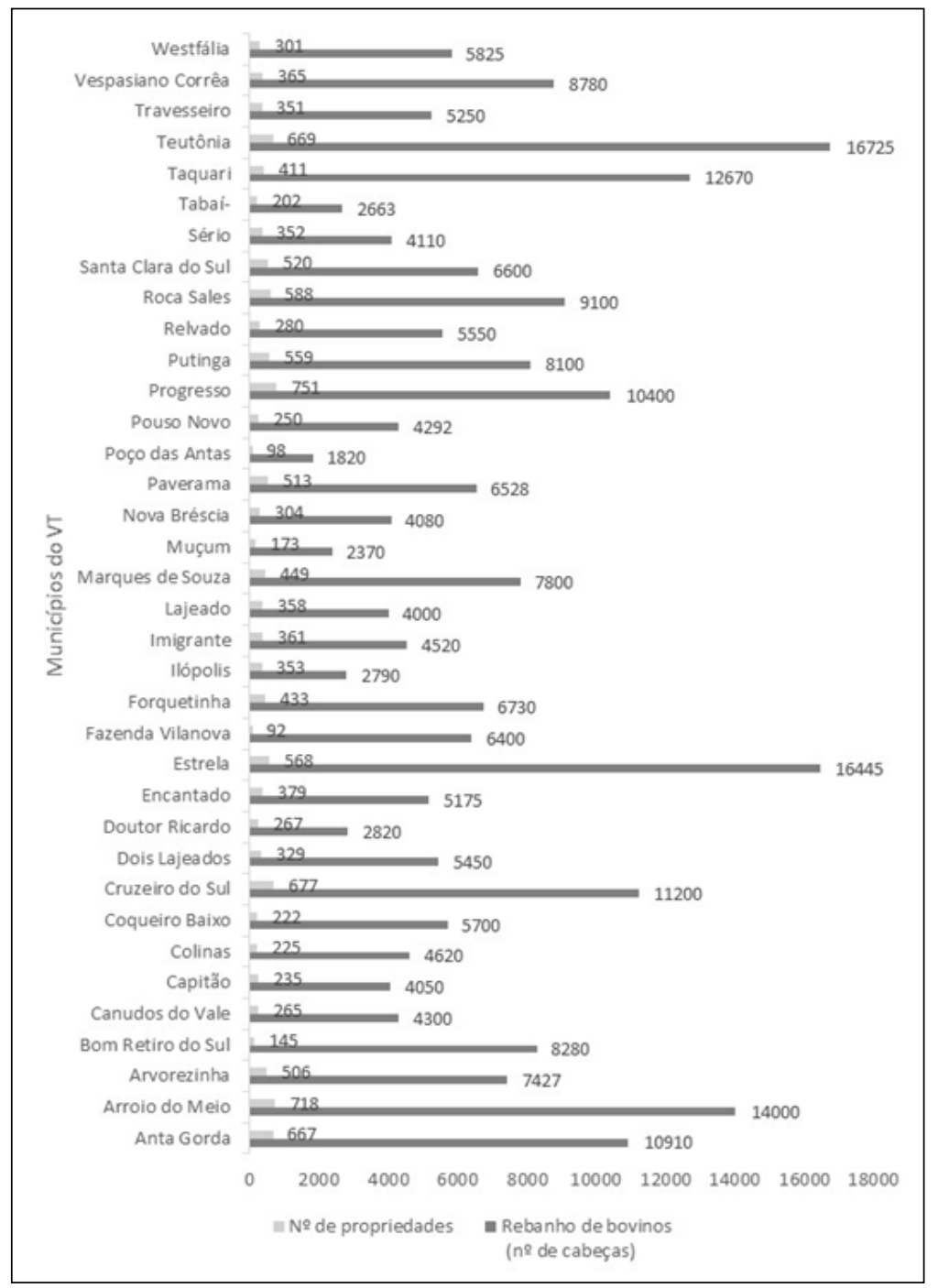

Fonte: Dados da Pesquisa (2017) 
No VT a média de animais por propriedade é de 17 bovinos e o tamanho médio das propriedades de 18,7 ha. Em torno de 35\% das propriedades têm em média 5 vacas em lactação (FIGURA 4). Esta caracterização está de acordo com os dados do Censo Agropecuário do IBGE (2006) mostram que cerca de $85 \%$ do leite produzido no RS é proveniente de propriedades de até 50 hectares.

Figura 4 - Percentual de animais por propriedade rural produtoras de leite do VT.

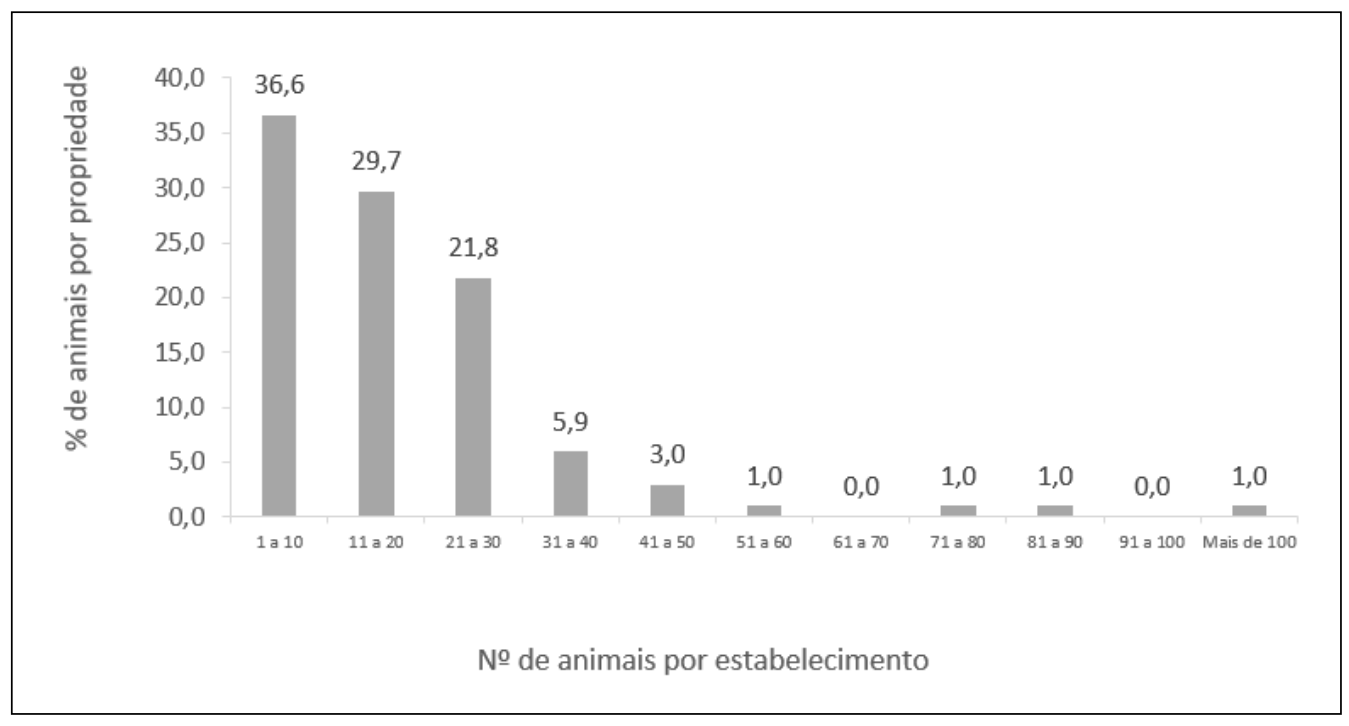

Fonte: Dados da Pesquisa (2017)

Em um cenário no qual a conservação ambiental assume importância crescente frente aos impactos causados pelas atividades produtivas, em especial a pecuária leiteira, torna-se necessário o conhecimento do uso e ocupação da terra e a cobertura vegetal das propriedades.

Assim, foi feito um levantamento a campo, utilizando entrevistas como forma de coleta de dados e pode-se verificar que há seis classes diferentes de uso da terra, sendo pastagens, floresta nativa e agricultura as mais representativas. A figura 5 apresenta o percentual de uso de cada uma dessas classes nas propriedades analisadas. 
Figura 5 - Classes de uso da terra das propriedades produtoras de leite do Vale do Taquari/RS

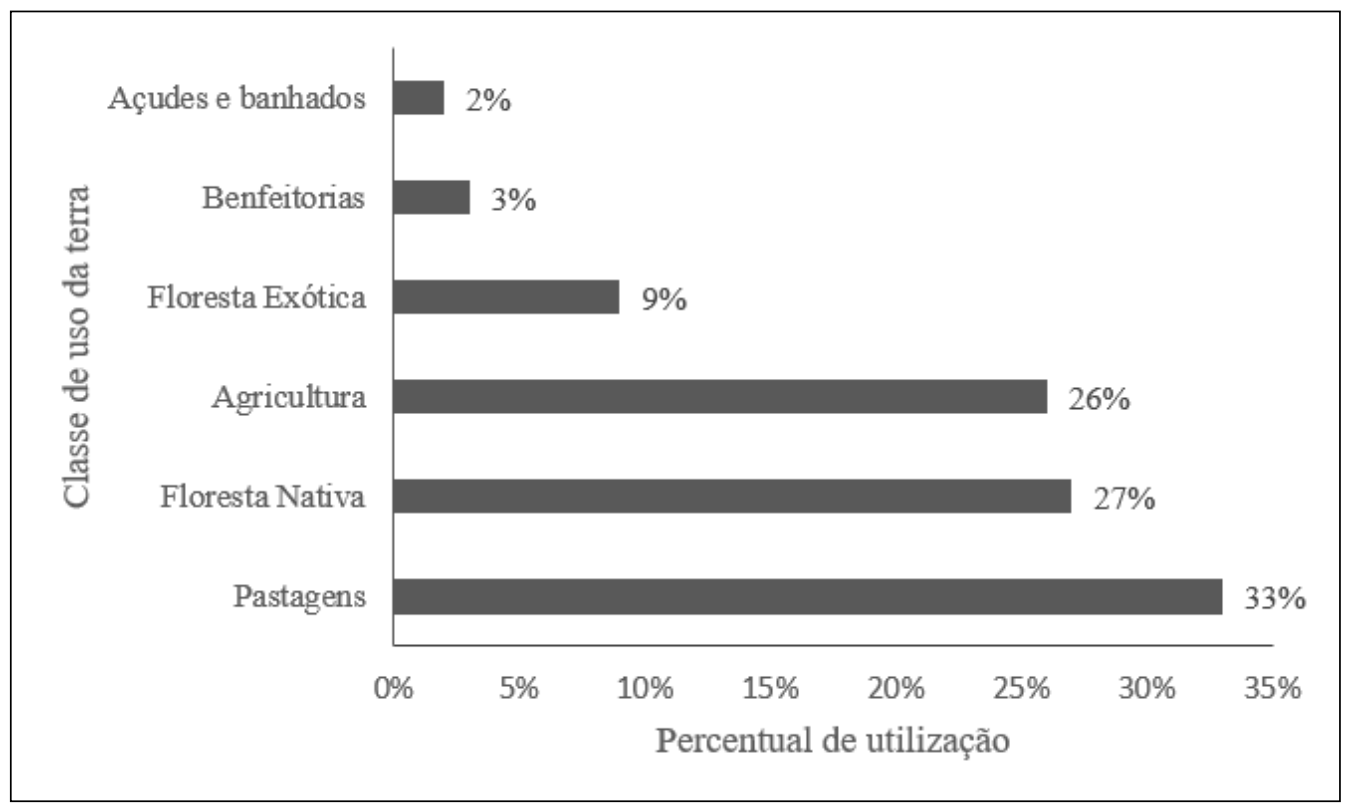

Fonte: Dados da Pesquisa (2017)

Quanto ao sistema de produção, $83,1 \%$ das propriedades criam o gado no regime extensivo, enquanto que no sistema semiconfinado foram 7,9\% e confinado apenas $2,0 \%$ das propriedades se utilizam desse modelo de criação.

No RS o órgão licenciador é a Fundação Estadual de Proteção Ambiental - RS - FEPAM, que recomenda que toda a instalação de criação de bovinos, em sistema de confinamento ou misto (semiconfinado), deve situar-se a uma distância mínima de qualquer corpo hídrico, (TABELA 1), e, ter piso de cimento impermeabilizado, de caliça, de solo cimento e/ou similares; além de canaletas de recolhimento dos dejetos, águas de lavagem até o local de armazenagem e tratamento. Os pisos das baias deverão apresentar impermeabilização para evitar a contaminação de águas subterrâneas; permitir raspagens; serem confeccionados em cimento, caliça, solo cimento e/ou similares; com canaletas de recolhimento dos dejetos e das águas de lavagem até o local de armazenagem e tratamento (RIO GRANDE DO SUL, 2017). 
Tabela 1 - Distanciamento mínimo das instalaçóes em relação aos corpos hídricos, a ser somado ao distanciamento previsto no Código Florestal Federal, conforme o porte do empreendimento e o tipo de produção (confinada e semiconfinada), no caso da utilização de manejo de dejetos líquidos

\begin{tabular}{l|c}
\hline Porte $^{*}$ & Distância $(\mathrm{m})$ \\
\hline Mínimo & 25 \\
\hline Pequeno & 25 \\
\hline Médio & 50 \\
\hline Grande & 100 \\
\hline Excepcional & 150 \\
\hline
\end{tabular}

* OBS: para propriedades de até 4 módulos rurais, explorada em regime de agricultura familiar, devidamente comprovada por entidade setorial, as distâncias poderiam ser reduzidas em até $50 \%$ para os portes mínimo, pequeno e médio, mediante medidas compensatórias aprovadas pelo órgão ambiental, desde que fiquem no mínimo, a 30/50 metros ou outras distâncias d'água (rios, ... nascentes, de acordo com o Código Florestal).

Fonte: Rio Grande do Sul (2017).

A Lei Complementar No 140 de 2011, estabeleceu que são açóes administrativas dos Municípios, observadas as atribuiçóes dos demais entes federativos, a de promover o licenciamento ambiental das atividades ou empreendimentos que causem ou possam causar impacto ambiental de âmbito local, conforme tipologia definida pelos respectivos Conselhos Estaduais de Meio Ambiente, considerados os critérios de porte, potencial poluidor e natureza da atividade (BRASIL, 2011).

O Código Estadual do Meio Ambiente do RS determina que caberá aos municípios o licenciamento ambiental dos empreendimentos e atividades consideradas como de impacto local, bem como aquelas que lhe forem delegadas pelo Estado por instrumento legal ou convênio. $\mathrm{O}$ órgão ambiental competente proporá, em razão da natureza, característica e complexidade, a lista de tipologias dos empreendimentos ou atividades consideradas como de impacto local, ou quais deverão ser aprovados pelo Conselho Estadual do Meio Ambiente.

Nesta esteira, o Conselho Estadual de Meio Ambiente - CONSEMA do Rio Grande do Sul, definiu que o sistema confinado e semiconfinado são passiveis de licenciamento ambiental (Resolução CONSEMA No 288/2014). Esta resolução define as tipologias, que causam ou que podem causar impacto de âmbito local, definindo que os municípios que tiverem órgão ambiental capacitado e conselho municipal de meio ambiente podem licenciar empreendimentos que situarem-se dentro dos limites municipais, cabendo ao Estado licenciar empreendimentos que extrapolem os limites municipais (RIO GRANDE DO SUL, 2014).

Entretanto, a Portaria FEPAM no 98/2015, determina que fiquem isentas de Licenciamento Ambiental Estadual, no Estado do Rio Grande do Sul, as atividades de criação de bovinos em sistema extensivo a campo e de criação de ovinos em sistema extensivo a campo (RIO GRANDE DO SUL, 2015). 
A dificuldade de interpretação da hierarquia de legislaçóes sobre o tema e, a falta de fiscalização e normatização dos procedimentos administrativos da atividade, fizeram com que até pouco tempo não houvesse restriçôes de instalação e funcionamento da atividade de pecuária leiteira no Estado. Entretanto, após a publicação da Lei Complementar no 140 de 2011, colocou todos os produtores no limbo da insegurança jurídica (BRASIL, 2011).

Quanto à classe de ocupação das propriedades pesquisadaspercebe-se que $41,6 \%$ das áreas estão cobertas com vegetação nativa, $24,8 \%$ com pastagens temporárias, $20,8 \%$ com pastagens permanentes e o restante com benfeitorias (2\%), agricultura (5\%) e cinco por cento não identificou o uso da terra.

Ao analisar os mapas das propriedades observou-se a tipologia das APP presentes e constatou-se que $17,8 \%$ das propriedades possuem açudes ou lagos, $7,9 \%$ apresentam-se em áreas de topo de morro, $4,9 \%$ com declividade superior $\mathrm{A} 45^{\circ}, 8,9 \%$ possuem áreas úmidas em suas propriedades, $25,7 \%$ nascentes e $22,8 \%$ alguma margem de rio (FIGURA 6).

Figura 6 - Percentual de Áreas de Preservação Permanentes identificadas nas pequenas propriedades produtoras de leite do VT

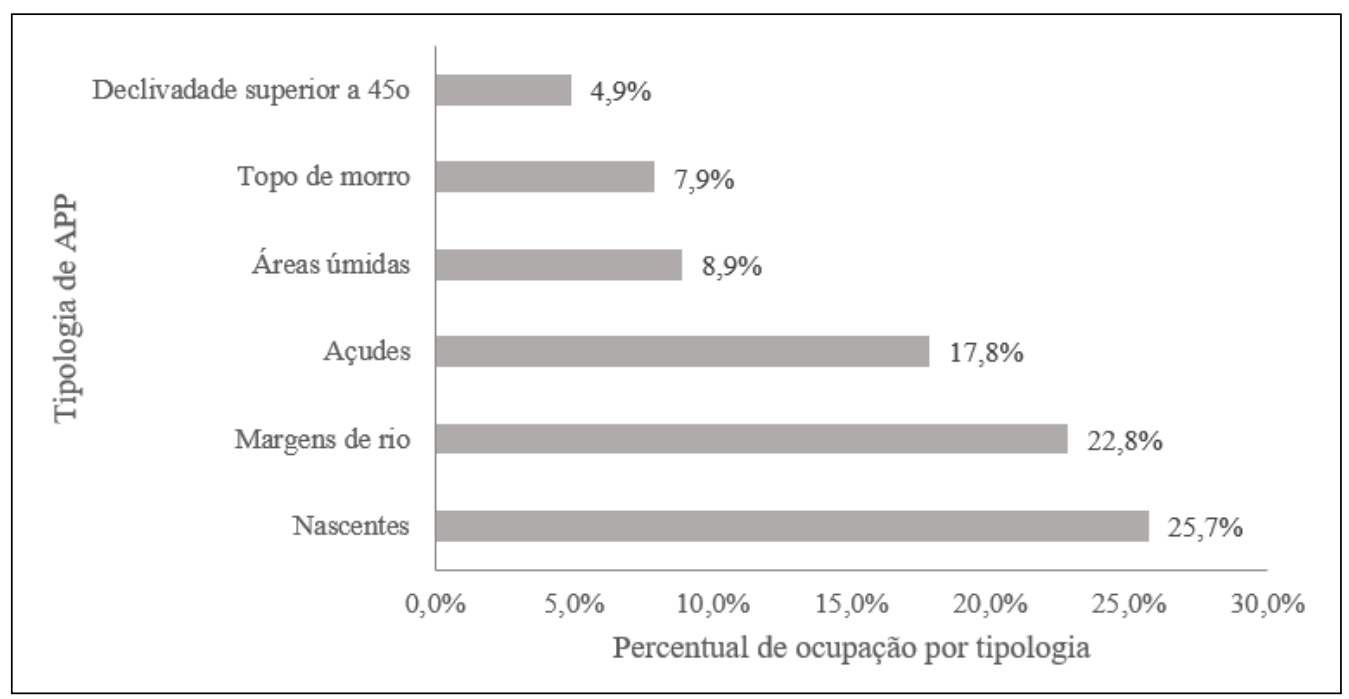

Fonte: Dados da Pesquisa (2017).

Em relação às APPs, observou-se que das 101 propriedades avaliadas, 75 têm área com cobertura de vegetaçáo nativa acima de $20 \%$ e apenas 20 propriedades apresentaram cobertura inferior a $20 \%$. Todas as propriedades de dois a quatro módulos fiscais possuem mais do que $20 \%$ da sua área com cobertura vegetal nativa, portanto, área suficiente para averbação da RL.

Para uma melhor análise das propriedades do VT em relação a RL a amostra foi dividida em duas categorias (FIGURA 7). Na primeira categoria estão as propriedades de até dois módulos fiscais que se subdividem em propriedades com áreas de cobertura vegetal 
acima de $20 \%$ e cobertura vegetal abaixo de $20 \%$. O segundo grupo com área acima de dois módulos fiscais não apresentou nenhuma área com cobertura vegetal inferior a $20 \%$.

Figura 7 - Distribuição das propriedades avaliadas em módulos fiscais e a necessidade de recomposição de vegetação nativa para fins de composição da RL de acordo com o artigo 15 do NCFF

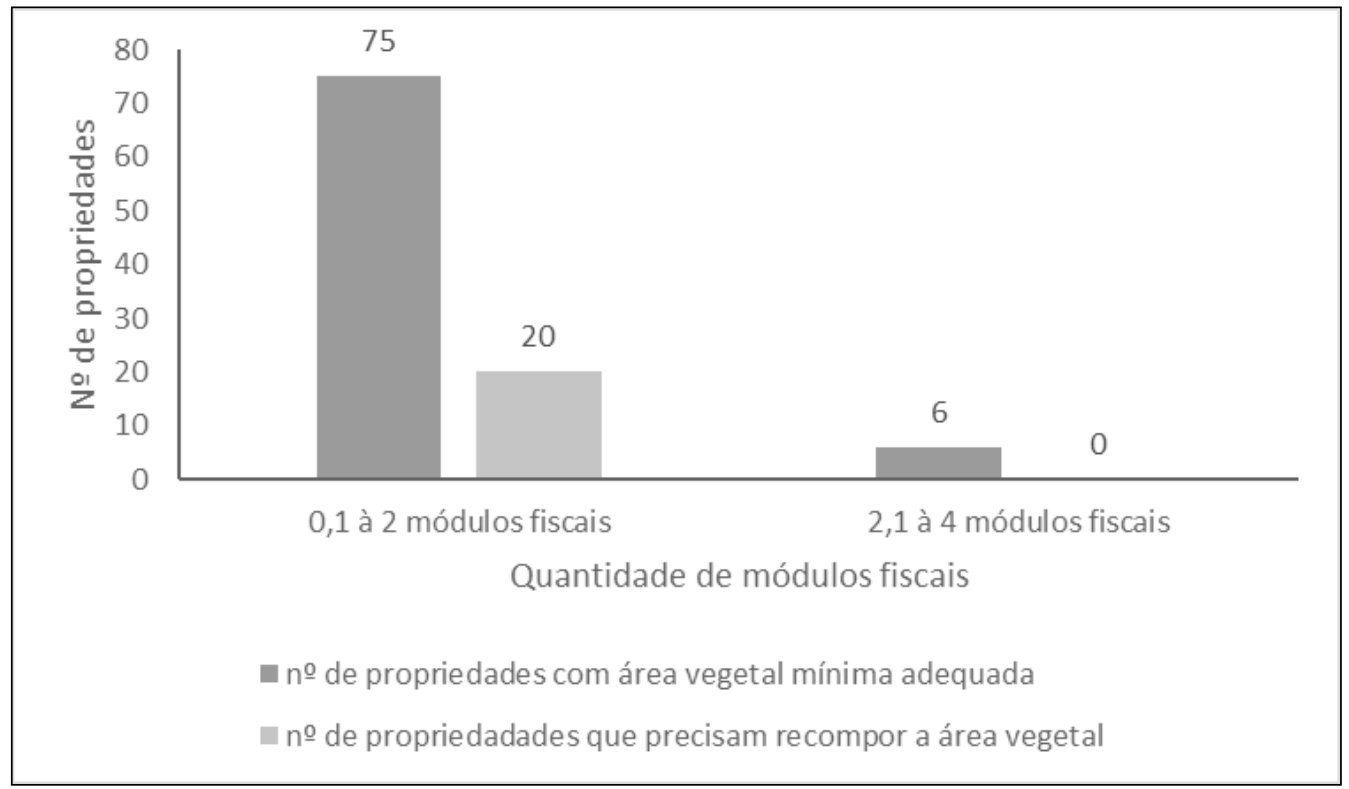

Fonte: Dados da Pesquisa (2017).

Os percentuais destinados à RL variam conforme a localização do imóvel, correspondendo, na Amazônia Legal a 80\%, no imóvel localizado em área de floresta, 35\% no situado em área de cerrado e $20 \%$ no situado em área de campos gerais. Em todas as demais regióes do país, incluindo o RS, o percentual destinado à RL deve corresponder a 20\% do imóvel (BRASIL, 2012).

A legislação estabelece que todo imóvel rural deve manter área com cobertura de vegetação nativa, a título de RL, sem prejuízo da aplicação das normas sobre as APP, observados os percentuais mínimos em relação à área do imóvel, excetuados os casos em que os proprietários ou possuidores de imóveis rurais tenham realizado a supressão de vegetação nativa respeitando os percentuais de RL previstos pela legislação em vigor à época em que ocorreu a supressão (BRASIL, 2012).

Segundo o NCFF, estes proprietários estão dispensados de promover a recomposição, compensação ou regeneração, para os percentuais exigidos em lei uma vez que tenham respeitados os percentuais da época e estejam utilizando a terra com alguma atividade agrossilvipastoril. Esta comprovação dar-se-á por documentos tais como: a descrição de fatos históricos de ocupação da região, registros de comercialização, dados agropecuários da atividade, contratos e documentos bancários relativos à produção, e por todos os outros meios de prova em direito admitidos (BRASIL, 2012). 
Para aqueles que necessitarem a recomposição a mesma deverá atender os critérios estipulados pelo órgão competente do SISNAMA e ser concluída em até 20 (vinte) anos, abrangendo, a cada dois anos, no mínimo 1/10 (um décimo) da área total necessária à sua complementação.

Já os imóveis rurais que detinham, em 22 de julho de 2008, área de até quatro módulos fiscais e que possuam remanescente de vegetação nativa em percentuais inferiores a $20 \%$, a RL será constituída com a área ocupada com a vegetação nativa existente em 22 de julho de 2008, vedada novas conversóes para uso alternativo do solo (BRASIL, 2012). Este aspecto da legislação se aplica aos pequenos imóveis rurais da agricultura familiar que estão tipificados no presente projeto. Para estes não haverá a necessidade de recomposição da RL a não ser a manutenção das APP e dos remanescentes de vegetação nativas que estavam na propriedade em 2008. Para estes o percentual será variável, podendo em alguns casos específicos ser de zero RL. No caso da pesquisa, sete propriedades apresentaram zero de remanescente de vegetação nativa, ou seja, não tinham nenhum tipo de APP ou mesmo remanescentes de vegetação fora da APP. E, 41 propriedades índices inferiores a $20 \%$ de remanescente de vegetação nativa.

No entanto, alguns aspectos da legislação são mais agravantes, entre eles está a possibilidade de não haver recuperação nenhuma de APP de mananciais hídricos tendo em vista que se os proprietários ou possuidores dos imóveis rurais que, em 22 de julho de 2008, detinham até quatro módulos fiscais e desenvolviam atividades agrossilvipastoris nas áreas consolidadas em APP. A legislação garante que a exigência de recomposição, somadas todas as APP do imóvel, não poderão ultrapassar $10 \%$ (dez por cento) da área total do imóvel para imóveis rurais com área de até dois módulos fiscais, e, 20\% (vinte por cento) da área total do imóvel, para imóveis rurais com área superior a dois e de até quatro módulos fiscais.

Este aspecto precisa ser melhor avaliado pois a expectativa de recuperação de APP de curso d'água, estipulados pelos dispositivos transitórios do NCFF, principalmente o disposto no artigo 61- A, poderão não ser suficiente para atender a necessidade de retenção de materiais lixiviados pela ação da chuva ou mesmo de erosão do solo pelas atividades antrópicas.

A expectativa de não ter uma largura mínima de cinco metros nos mananciais, devese ao fato que a média de tamanho das propriedades do Vale do Taquari são de 16 ha, e, a largura de preservação das APP para estes casos será de apenas cinco metros. A largura da APP não leva em consideração a largura do manancial. Ou seja, a propriedade poderá estar às margens de um curso d'água de 200 metros de largura que ela terá o mesmo direito de manter apenas cinco metros de APP do que se estivesse margeando um curso d'água de um metro de largura ou menos. Ou mesmo, o produtor poderá ter uma área com declividade superior à $45^{\circ}$ ou em topo de morro que atenda o percentual de $10 \%$ ou $20 \%$ e nestes casos ele estará desobrigado de manter as demais APP de curso d'água, por exemplo.

Milaré (2015) lembra que concebida como direito fundamental, a propriedade não é, contudo, um direito que possa erigir-se na suprema condição de ilimitado e inatingível. Daí o acerto do legislador em proclamar, de maneira veemente, que o uso da propriedade será condicionado ao bem-estar social e à defesa do meio ambiente. Assim sendo, a manutenção das APP são fundamentais para a gestão das bacias hidrográficas, 
pois contribuem para a estabilidade dos ciclos hidrológicos e biogeoquímicos visando a dar condiçóes de sustentabilidade à agricultura. Intervençóes nas APP para abertura de novas áreas agrícolas poderá comprometer, no futuro, a reposição de água nos aquíferos, a qualidade de água superficial e subterrânea, perda de solo, ameaças à saúde humana e degradação dos mananciais, além de comprometer a produção de alimentos. $\mathrm{O}$ papel regulador dos ciclos naturais realizado pelas APP é fundamental para a manutenção do equilíbrio ecológico (TUNDISI; TUNDISI, 2010).

Da análise dos deveres fundamentais atribuídos ao Estado para assegurar a efetividade do direito ao meio ambiente ecologicamente equilibrado, pode ser inferida a existência de um verdadeiro regime jurídico-constitucional dos espaços territoriais especialmente protegidos. Assim, o legislador poderá considerar de preservação permanente, quando declaradas de interesse social por ato do Chefe do Poder Executivo, as áreas cobertas com florestas ou outras formas de vegetação destinadas a uma ou mais finalidades, entre elas, a de conter a erosáo do solo e mitigar riscos de enchentes e deslizamentos de terra e de rocha, assim como, a proposição de intervençóes para a prevenção e o controle de riscos geotécnicos e de inundaçôes e, nas áreas urbanas a avaliaçẫo dos riscos ambientais.

A legislação ressalta que em todos os casos previstos no NCFF, o Poder Público, verificada a existência de risco de agravamento de processos erosivos ou de inundaçóes, determinará a adoção de medidas mitigadoras que garantam a estabilidade das margens e a qualidade da água, após deliberação do Conselho Estadual de Meio Ambiente ou de órgão colegiado estadual equivalente.

Talvez a alternativa seja recorrer a pesquisa de Rempel et al. (2012), que apresentaram uma proposta metodológica para a avaliação da sustentabilidade ambiental de propriedades produtoras de leite. Dessa forma é possível averiguar processos da atividade que estejam em desconformidade com a sustentabilidade, visando proporcionar às propriedades uma unidade de medida objetiva de impacto, a qual poderá auxiliar os proprietários como forma de minimizar seus os impactos ambientais da atividade.

Segundo Cyrne et al. (2015), para que a região do VT possa manter e avançar em sua competitividade, é necessário que as empresas e as próprias cadeias sejam gerenciadas de forma eficaz. Segundo os autores, ao tomar consciência dessa nova situação, as empresas devem se movimentar para atender às exigências legais, à fiscalização. É necessário ainda, prestar atenção os custos envolvidos e buscar acesso à tecnologia e informação. Assim como, estar atento aos requisitos apresentados pelo mercado consumidor, que passou a exigir produtos "ambientalmente corretos".

Será necessário um esforço conjunto dos diferentes atores para qualificar a gestão das propriedades produtoras de leite do VT, e encontrar uma nova forma de produzir e consumir, pois só assim poder-se-á mitigar os efeitos nocivos sobre o meio ambiente (CYRNE; HAETINGER; REMPEL, 2015).

Precisamos destacar a importância do gerenciamento dos recursos naturais e dos resultados das atividades desenvolvidas no meio rural, visando ao controle dos custos de produção sem perder a rentabilidade da atividade e sem comprometer a sustentabilidade do sistema. 


\section{CONCLUSÃO}

Atendendo ao objetivo da presente pesquisa de avaliar a conjuntura da RL das propriedades rurais com produção de leite no VT, conclui-se que $75 \%$ das propriedades amostradas estáo atendendo os princípios legais do NCFF e os demais $25 \%$ se enquadram nos dispositivos normativos transitórios da nova lei. Isto se deve ao fato que a legislação determina que para os imóveis rurais que detinham, em 22 de julho de 2008, área de até quatro módulos fiscais e que possuam remanescente de vegetação nativa em percentuais inferiores ao previsto no art. 12 (20\%), a RL será constituída com a área ocupada com a vegetação nativa existente em 22 de julho de 2008, vedada novas conversóes para uso alternativo do solo. Assim, pode-se concluir que as propriedades do VT estáo atendendo as primícias do NCFF em todos seus aspectos, exceto, os casos em que o poder público verificar a existência de risco de agravamento de processos erosivos ou de inundaçóes, determinará a adoçáo de medidas mitigadoras que garantam a estabilidade das margens e a qualidade da água, após deliberação do Conselho Estadual de Meio Ambiente ou de órgão colegiado estadual equivalente.

Entretanto, ainda há a necessidade de serem preenchidas algumas lacunas de forma que se tenha sustentabilidade da atividade de pecuária leiteira. Mesmo que a segurança alimentar se constitua em um dos maiores desafios da humanidade, é inevitável que os proprietários realizem algumas adequaçóes ambientais de uso da terra e manejo da atividade que permita a manutenção da pecuária de leite e a preservação ambiental. Para tanto, uma das alternativas é a criação de bovinos de leite em sistema confinado, tendo em vista o tamanho das propriedades e a facilidade de manejo dos resíduos. No entanto, alguns aspectos precisam ser superados, entre eles os custos e a burocracia de licenciamento ambiental. Atualmente a pecuária em sistema intensivo é caracterizada como de alto impacto ambiental eleva os investimentos em precaução como forma de minimizar os riscos ambientais.

Outra forma de se garantir a manutenção das atividades de produção de leite na região do VT, é reconhecendo a importância da atividade e, ao mesmo tempo a preservaçáo de algumas áreas, entre elas, as áreas de mananciais hídricos. Para tanto, é necessário alguns cuidados em especial no Programa de Regularização Ambiental - PRA, de forma que leve em consideração a sustentabilidade das propriedades principalmente nos aspectos sociais e econômicos, onde mantenha um tratamento diferenciado para a agricultura familiar.

\section{REFERÊNCIAS}

AMADO, T. F. D. Legislaçáo Comentada para Concursos - Ambiental. São Paulo: Editora Método, 2015.

BRASIL. Constituiçáo Brasileira. Brasília, DF, 1934.

BRASIL. Lei No 12.651, de 25 de maio de 2012. Brasília, DF, 2012.

BRASIL. Medida Provisória 2166 e 67 de 24 de agosto de 2001 - Brasília, DF, 2001. 
BRASIL. SICAR - Sistema Nacional de Cadastro Ambiental Rural. Ministério do Meio Ambiente. O que é o Cadastro Ambiental Rural. 2014. Disponível em: <http://www. car.gov.br/\#/sobre>. Acesso em: 06 jun. 2016.

CYRNE, C. C. da S. Indicadores de gestáo em propriedades produtoras de leite do Vale do Taquari - RS - Um estudo comparativo com as propriedades da regiáo da Galícia - Espanha. 220 fl. 2015. Tese (Doutorado) - Curso de Doutorado em Ambiente e Desenvolvimento, Centro Universitário UNIVATES, Lajeado, 18 set. 2015. Disponível em: <http://hdl.handle.net/10737/987>.

CYRNE, C.C.S.; REMPEL, C.; HAETINGER, C. ECKHARDT, R. R . Avaliação da gestão ambiental em pequenas propriedades produtoras de leite no vale do taquari a partir do uso da matriz importância x desempenho. Redes, Santa Cruz do Sul, v. 20, p. 176$194,2015$.

EMBRAPA. Módulos Fiscais. Brasília: EMBRAPA, s.a. Disponível em: <https://www. embrapa.br/codigo-florestal/area-de-reserva-legal-arl/modulo-fiscal $>$. Acesso em 06 de agosto de 2018 .

IBGE - INSTITUTO BRASILEIRO DE GEOGRAFIA E ESTATÍSTICA. Censo Agropecuário 2006. Rio de Janeiro, 2009. Disponível em: <http://www.sidra.ibge.gov. br>. Acesso em: 11 de outubro de 2016.

IBGE - INSTITUTO BRASILEIRO DE GEOGRAFIA E ESTATÍSTICA. Produçáo da Pecuária Municipal - 2013. Rio de Janeiro: IBGE, 2014. Disponível em: <http://www. sidra.ibge.gov.br>. Acesso em: 12 de outubro de 2016.

MILARÉ, E. Direito Ambiental. São Paulo: Revista dos Tribunais, 2015.

REMPEL, C. et al. Proposta metodológica de avaliação da sustentabilidade ambiental de propriedades produtoras de leite. Tecno-lógica, Santa Cruz do Sul, v. 16, n. 1, p.48-54, 2012.

RIBEIRO, A. C. F; BRITES, R. S.; JUNQUEIRA, A. M. R. Os aspectos ambientais no processo decisório do produtor rural: estudo de caso Núcleo Rural Taquara. Revista Brasileira de Engenharia Agrícola e Ambiental, Campina Grande, v. 10, n. 3, 2006.

RIO GRANDE DO SUL, Decreto Estadual No 52.431, de 23 de junho de 2015. Porto Alegre, 2015.

RIO GRANDE DO SUL, Portaria FEPAM N.o 98/2015. Dispóe sobre a isenção do licenciamento para criaçáo de bovinos e ovinos de corte em sistema extensivo a campo no estado do Rio Grande do Sul. Porto Alegre, 2015. 
RIO GRANDE DO SUL. Secretaria de Ambiente e Desenvolvimento do Rio Grande do Sul, 2014. Resoluçáo CONSEMA 288 de 2014. Porto Alegre: 2014. Disponível em: < http://www.sema.rs.gov.br/resolucoes> Acessado em: 10 de junho de 2016.

RIO GRANDE DO SUL. Secretaria de Ambiente e Desenvolvimento do Rio Grande do Sul, 2017. Inventário Florestal Contínuo do Rio Grande do Sul. Disponível em: $<$ http://www.sema.rs.gov.br/conteudo.asp?cod_menu=355> . Acessado em: 12 de outubro de 2016.

RIO GRANDE DO SUL. Critérios técnicos para o licenciamento ambiental de novos empreendimentos destinados à bovinocultura confinada e semiconfinada. Porto Alegre: FEPAM, 2017. Disponível em: <http://www.fepam.rs.gov.br/central/diretrizes/ diret_bovinos_novos.pdf $>$. Acesso em: 06 de agosto de 2018

SODRÉ, A.DE A., Novo Código Florestal Comentado. Leme/ São Paulo: Mizuno. 2013.

TUNDISI, J.G.; TUNDISI, T.M. Impactos potenciais das alteraçôes do Código Florestal nos recursos hídricos. Biota Neotropica, Campinas. v. 10, n. 4, p. 67-76, 2010. 